УДК 621.928:167

(C) I.М. Дударєв, д.т.н., О.С. Хільчук, І.А. Кіпень

Луцький національний технічний університет

\title{
ДОСЛІДЖЕННЯ РУХУ ЧАСТИНКИ СИПКОГО МАТЕРІАЛУ РЕШЕТОМ СЕПАРАТОРА НОЖИЧНОГО ТИПУ
}

У статті запропонована конструкиія гравітаційного сепаратора сипких матеріалів ножичного типу $i$ представлені результати теоретичних досліджень руху частинки сипкого матеріалу решетом сепаратора. У результаті дослідження одержані залежності та умови для обгрунтування раціональних параметрів сепаратора з урахуванням фізико-механічних властивостей сипкого матеріалу.

\section{СЕПАРАТОР, СЕПАРУВАННЯ, РЕШЕТО, СИПКИЙ МАТЕРИАЛ, РУХ ЧАСТИНКИ МАТЕРІАЛУ}

Постановка проблеми. Розроблення обладнання для сепарування сипких матеріалів чи їх сумішей для різних галузей промисловості має здійснюватися у напрямі зниження енерговитрат на проведення технологічного процесу. Один із напрямів зниження енерговитрат на сепарування та підвищення його ефективності - це врахування під час вибору способу сепарування фізико-механічних властивостей сипкого матеріалу або суміші матеріалів. Найбільш перспективними у цьому напрямі конструкціями сепараторів $\epsilon$ гравітаційні сепаратори, принцип роботи яких заснований на урахуванні фізико-механічних властивостей сипких матеріалів і в яких, в переважній більшості, не витрачається електроенергія на привод робочих органів чи поверхонь. Запропоновані нові конструкції гравітаційних сепараторів потребують здійснення подальших теоретичних та експериментальних досліджень $з$ метою обгрунтування їх раціональних параметрів. Тому дослідження, спрямовані на обгрунтування раціональних параметрів конструкції запропонованого гравітаційного сепаратора ножичного типу, $\epsilon$ актуальними.

Аналіз останніх досліджень і публікацій. Обгрунтуванню конструкцій гравітаційних сепараторів, їх параметрів та дослідженню роботи присвячені наукові праці вітчизняних та закордонних науковців [1 - 6]. Для ефективної роботи гравітаційних сепараторів необхідно обгрунтовувати такі раціональні параметри конструкцій, за яких буде забезпечено рух сипкого матеріалу чи суміші матеріалів робочими поверхнями 
сепаратора без утворення заторів. Тому в більшості проведених досліджень визначалися умови руху сипкого матеріалу чи суміші матеріалів робочими поверхнями сепараторів. Разом 3 тим, запропоноване технічне рішення гравітаційного сепаратора ножичного типу має відмінності в конструкції від відомих конструкцій, i, відповідно, потребує додаткових досліджень, зокрема теоретичних, для обгрунтування раціональних параметрів.

Мета дослідження - дослідити рух частинки сипкого матеріалу решетом гравітаційного сепаратора ножичного типу та одержати залежності і умови для обгрунтування раціональних параметрів сепаратора.

Результати дослідження. Для сепарування сипких матеріалів (зерно, насіння сільськогосподарських культур або сипкі матеріали, що підлягають сепаруванню за розмірами чи формою) пропонується конструкція гравітаційного сепаратора ножичного типу (рис. 1), що містить сепарувально-важільний механізм та бункер. Сепарувально-важільний механізм містить систему сепарувальних секцій-важелів, які з'єднано хрестоподібно (по типу “ножиці”) за допомогою шарнірів. Кожна сепарувальна секціяважіль має раму, між боковинами якої розташовані пересипні полиці, кожна з яких, у свою чергу, містить плоске решето, під яким розташований піддон. У кінці кожного решета та піддона встановлені спрямовуючі пластини, які спрямовують певну фракцію сипкого матеріалу в необхідний рукав, який, в свою чергу, спрямовує цю фракцію на початок наступного решета чи піддону, що розташовані нижче. Рама однієї нижньої сепарувальної секціїважеля кінцями закріплена на платформі за допомогою шарнірів, а в отворах кінців рами другої нижньої сепарувальної секції-важеля встановлена вісь, на якій розташовані ролики, що виконані із можливістю руху платформою. Крім того, до нижньої сепарувальної секції-важеля приєднано передачу гвинт-гайка, чим забезпечено можливість зміни кута $\alpha$ нахилу плоских решіт до горизонту в межах від найменшого до найбільшого значення.

Перед початком роботи сепаратора здійснюють встановлення сепарувально-важільного механізму у положення, в якому буде забезпечено необхідний кут $\alpha$ нахилу плоских решіт до горизонту, за якого буде забезпечено рух сипкого матеріалу решетами самопливом. На усіх пересипних полицях встановлюють плоскі решета 3 отворами необхідного розміру та форми. Під нижніми сепарувальними секціями-важелями розташовують накопичувачі для крупної та дрібної фракцій сипкого матеріалу (складових суміші сипких матеріалів). Далі завантажують у бункер 
сипкий матеріал та відкривають заслінки. Сипкий матеріал самопливом надходить на плоскі решета пересипних полиць верхніх сепарувальних секцій-важелів. Оскільки процес сепарування проходить аналогічно на пересипних полицях усіх сепарувальних секцій-важелів, то розглянемо перебіг цього процесу на одній пересипній полиці.
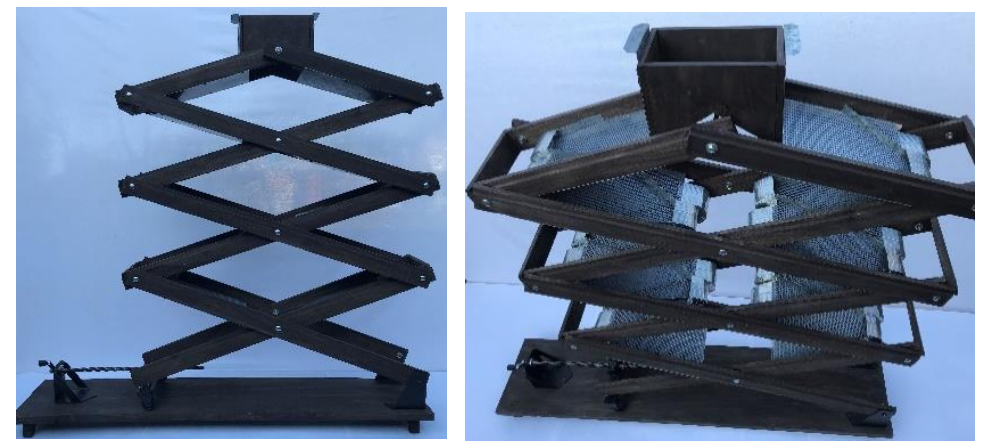

Рис. 1 - Сепаратор сипких матеріалів ножичного типу

Під час руху сипкого матеріалу похилим плоским решетом вниз його дрібна фракція проходить через отвори у решеті та опиняється на піддоні. Крупна фракція сипкого матеріалу 3 невідокремленою частиною дрібної фракції рухається самопливом решетом вниз до спрямовуючої пластини, яка спрямовує фракції у рукав, що, у свою чергу, спрямовує крупну фракцію 3 невідокремленою частиною дрібної фракції на верхню частину решета пересипної полиці сепарувальної секції-важеля, що розташована нижче. Пересипання крупної фракції сипкого матеріалу з невідокремленою частиною дрібної фракції із решета однієї пересипної полиці на решето другої пересипної полиці, що розташована нижче, а також зміна напрямку потоку сипкого матеріалу, сприяють інтенсифікації процесу сепарування. У цей же час відокремлена дрібна фракція самопливом рухається вниз поверхнею піддона сепарувальної секції-важеля та спрямовуючою пластиною спрямовується на піддон пересипної полиці сепарувальної секції-важеля, що розташована нижче. Далі фракції сипкого матеріалу самопливом рухаються 3 однієї пересипної полиці на другу зверху вниз. Необхідно зауважити, що сипкий матеріал рухається з бункера двома окремими потоками (лівим $\mathrm{i}$ правим) та процес сепарування кожного з яких відбувається окремо, 
але аналогічно. Фракції сипкого матеріалу 3 решіт та піддонів нижніх сепарувальних секцій-важелів спрямовуються у відповідні накопичувачі.

Дослідимо рух частинки сипкого матеріалу $M$, яку приймаємо за матеріальну точку, поверхнею решета сепаратора ножичного типу. Нехай плоске решето встановлено під кутом $\alpha$ до горизонтальної площини, а спрямовуюча пластина під кутом $\beta$ до рами секції сепаратора (рис. 2, а). Під час руху частинки матеріалу $M$ поверхнею решета вниз на неї діють: сила ваги $m g(\mathrm{H})$, сила тертя $F_{\text {mep. }}(\mathrm{H})$ та нормальна реакція $N(\mathrm{H})$ поверхні решета. Складемо рівняння руху частинки матеріалу $M$ в системі координат $x A y$ :

$$
\left.\begin{array}{l}
m \ddot{x}=m g \sin \alpha-F_{m e p .} ; \\
m \ddot{y}=N-m g \cos \alpha,
\end{array}\right\}
$$

де $m$ - маса частинки матеріалу, кг; $\ddot{x}, \ddot{y}$ - відповідно проекції вектора прискорення частинки матеріалу на осі $x$ та $y, \mathrm{~m} / \mathrm{c}^{2}$.

Оскільки на частинку матеріалу не діє жодна інша сила, окрім зазначених, то частинка рухатиметься без відриву від поверхні решета, i, відповідно, $\ddot{y}=0$. Ураховуючи зазначене вище, iз другого рівняння системи (1) визначимо нормальну реакцію поверхні решета, а також силу тертя:

$$
\begin{gathered}
N=m g \cos \alpha ; \\
F_{\text {mep. }}=f N=f m g \cos \alpha,
\end{gathered}
$$

де $f$ - коефіцієнт тертя частинки матеріалу по поверхні решета.

Для забезпечення руху частинки матеріалу $M$ решетом вниз (на рис. 2, а - це ділянка $A B$ траєкторії руху частинки матеріалу $M$ ), має виконуватися умова:

$$
\begin{gathered}
m g \sin \alpha>F_{\text {тер. }}, \text { звідки } \\
\operatorname{tg} \alpha>f, \text { де } f=\operatorname{tg} \varphi \text { та } \cos \alpha>0, \\
\alpha>\varphi,
\end{gathered}
$$

де $\varphi-$ кут тертя матеріалу, що сепарується, по поверхні решета, град.

Iз першого рівняння системи (1) визначимо швидкість частинки матеріалу $M$ вздовж решета та їі переміщення вздовж осі $x$ (рис. 2, а) за початкових умов $t_{0}=0, \dot{x}_{0}=0$ та $x_{0}=0$ :

$$
\begin{gathered}
\dot{x}=g t(\sin \alpha-f \cos \alpha), \\
x=\frac{g t^{2}}{2}(\sin \alpha-f \cos \alpha),
\end{gathered}
$$

де $t-$ час, с. 
Із рівняння (8) визначимо час, за який частинка матеріалу $M$ пройде вздовж решета шлях $x=l$ (рис. 2, a):

$$
t_{B}=\sqrt{\frac{2 l}{g(\sin \alpha-f \cos \alpha)}} .
$$

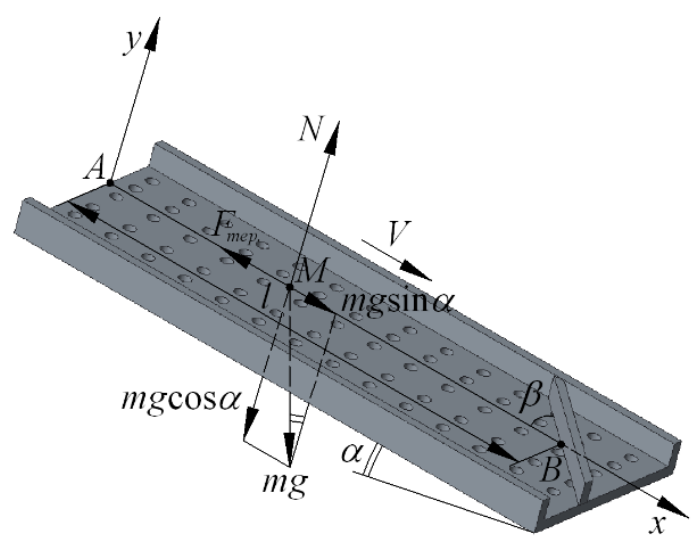

a

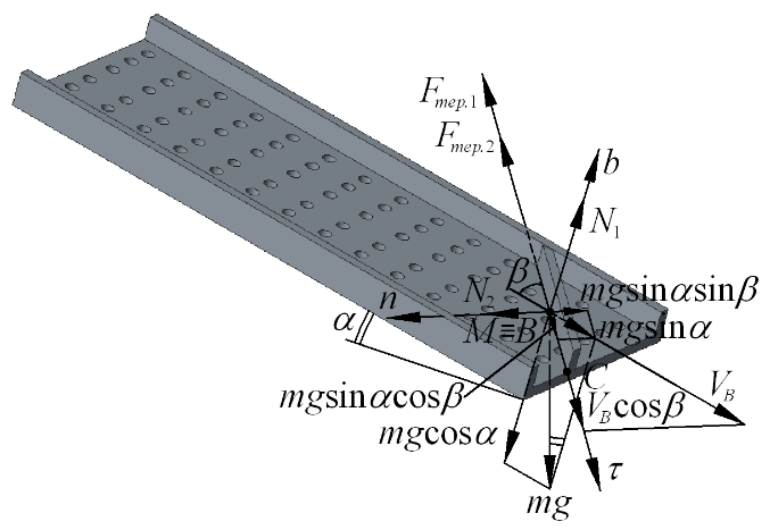

б

Рис. 2 - Схеми до пояснення руху частинки матеріалу $M$ решетом: a - на ділянці $A B$ траєкторії; б - на ділянці $B C$ траєкторії

У момент, коли частинка матеріалу $M$ досягає спрямовуючої пластини, тобто точки $B$ (рис. 2, а), іiі швидкість становитиме:

$$
V_{B}=\sqrt{2 g l(\sin \alpha-f \cos \alpha)} .
$$


Після досягнення спрямовуючої пластини частинка матеріалу $M$ починає рухатися вздовж неї. Визначимо, за якого значення кута $\beta$ встановлення спрямовуючої пластини частинка матеріалу $M$ буде здійснювати рух вздовж неї вниз. Розглянемо випадок післяударного руху частинки матеріалу $M$ без ії відскоку від спрямовуючої пластини (рис. 2, б). У цьому випадку нормальна складова швидкості (до поверхні спрямовуючої пластини) частинки матеріалу рівна нулю, тобто $V_{n}=0$. Нехай удар частинки матеріалу по поверхні спрямовуючої пластини відбувається без тертя, тоді тангенціальні проекції швидкості частинки матеріалу на вісь $\tau$ до $V_{B} \cos \beta$ та після $V_{\tau}$ удару рівні [7]:

$$
V_{\tau}=V_{B} \cos \beta \text {. }
$$

Для випадку, що розглядається, складемо систему рівнянь, яка описує в системі координат $n \tau b$ рух частинки матеріалу $M$ на ділянці $B C$ траєкторії іiі руху решетом (вздовж спрямовуючої пластини):

$$
\left.\begin{array}{l}
m \ddot{n}=N_{2}-m g \sin \alpha \sin \beta ; \\
m \ddot{\tau}=m g \sin \alpha \cos \beta-F_{m e p .1}-F_{m e p .2} ; \\
m \ddot{b}=N_{1}-m g \cos \alpha,
\end{array}\right\}
$$

де $\ddot{n}, \ddot{\tau}, \ddot{b}-$ відповідно проекції вектора прискорення частинки матеріалу на осі $n, \tau$ та $b, \mathrm{~m} / \mathrm{c}^{2} ; N_{1}, N_{2}$ - відповідно нормальні реакції поверхонь решета та спрямовуючої пластини, $\mathrm{H} ; F_{\text {mep. } 1}, F_{\text {mep.2 }}-$ відповідно сили тертя, що виникають внаслідок руху частинки матеріалу решетом та вздовж спрямовуючої пластини, Н.

Нехай рух частинки матеріалу $M$ відбувається лише вздовж спрямовуючої пластини, тобто осі $\tau$, тоді $\ddot{n}=0$ та $\ddot{b}=0$. Ураховуючи зазначене, із першого та третього рівнянь системи (12) визначимо нормальні реакції $N_{1}$ та $N_{2}$, а також сили тертя $F_{\text {mер.1 }}$ та $F_{\text {mep.2: }}$ :

$$
\begin{gathered}
N_{1}=m g \cos \alpha \text { та } N_{2}=m g \sin \alpha \sin \beta, \\
F_{m e p .1}=f N_{1}=f m g \cos \alpha \text { та } F_{\text {mep. } 2}=f N_{2}=f m g \sin \alpha \sin \beta .
\end{gathered}
$$

Рівняння (14) отримані за умови, що для матеріалів решета та спрямовуючої пластини однакове значення коефіцієнта тертя $f$.

Розв'яжемо друге рівняння системи (12) з урахуванням рівнянь (14) та початкових умов $t_{0}=0, \dot{\tau}_{0}=V_{\tau}=V_{B} \cos \beta$ та $\tau_{0}=0$ : 


$$
\begin{gathered}
\dot{\tau}=g t(\sin \alpha \cos \beta-f[\cos \alpha+\sin \alpha \sin \beta])+V_{B} \cos \beta, \\
\tau=\frac{g t^{2}}{2}(\sin \alpha \cos \beta-f[\cos \alpha+\sin \alpha \sin \beta])+V_{B} t \cos \beta,
\end{gathered}
$$

де $\dot{\tau}-$ швидкість частинки матеріалу під час ії переміщення вздовж осі $\tau$, м/с; $\tau$ - переміщення частинки матеріалу вздовж осі $\tau$, м.

Визначимо умову руху частинки матеріалу $M$ вздовж спрямовуючої пластини, тобто осі $\tau$ :

$$
m g \sin \alpha \cos \beta>F_{\text {mер.1 }}+F_{\text {mер.2 }} \text {, звідки }
$$

$\alpha>\operatorname{arctg}\left(\frac{f}{\cos \beta-f \sin \beta}\right)$, ящо $\cos \alpha>0$ та $(\cos \beta-f \sin \beta)>0$ (18)

де $\alpha$ - кут нахилу решета, рад.

У випадку невиконання умови (18), вздовж направляючої пластини будуть утворюватися затори із частинок матеріалу, який сепарується, що $є$ недопустимим. Таким чином, значення кута $\beta$ необхідно приймати, враховуючи умову (18). У цьому випадку будуть створені сприятливі умови для переміщення сипкого матеріалу робочими поверхнями сепаратора.

Висновоки. Запропонована конструкція гравітаційного сепаратора ножичного типу, що дозволяє здійснювати сепарування сипких матеріалів із різними фізико-механічними властивостями за рахунок зміни кута нахилу решіт. Крім того, запропонований сепаратор є компактним та зручним в експлуатації, а також не потребує енерговитрат на процес сепарування.

Одержані в результаті теоретичних досліджень залежності та умови дозволяють обгрунтувати раціональні параметри запропонованого сепаратора із урахуванням фізико-механічних властивостей сипкого матеріалу чи суміші матеріалів, що сепаруються.

\section{Література}

1. Заика П.М. Сепарация семян по комплексу физикомеханических свойств / П.М. Заика, Г.Е. Мазнев. - М.: Колос, 1978. - 287 c.

2. Карташевич С.М. Механико-технологические основы повышения эффективности механизированных комплексов для 
послеуборочной обработки зерна и семян: монография / С.М. Карташевич. - Минск : РУП “БелНИИагроэнерго”, 2001. - 288 с.

3. Богомолов О.В. Наукове обгрунтування енергозберігаючих процесів та обладнання для сепарації харчової сипкої сировини: автореф. дис. ...д-ра техн. наук: 05.18.12 / Богомолов Олексій Васильович; Харківський державний університет харчування та торгівлі. - Харків, 2006. - 34 с.

4. Єрмак В.П. Класифікація засобів сепарації та конструкцій машин для відбору насіння з високими посівними властивостями / В.П. Єрмак, Є.В. Богданов, А.А. Ільченок // Збірник наукових праць Луганського національного аграрного університету. - № 35. - Серія (Технічні науки). - Луганськ: ЛНАУ. - 2012. - С. 127 - 132.

5. Фалько О.Л. Наукове обгрунтування процесу фракціонування рослинної сировини: автореф. дис. ...д-ра техн. наук: 05.18.12 / Фалько Олександр Леонідович; Національний університет харчових технологій. - Київ, 2014. - 46 с.

6. Дударєв I.M. Розрахунок машин зі спіральними робочими поверхнями: монографія / I.М. Дударєв. - Луцьк: Інформ.-вид. відділ Луцького НТУ, 2017. - 228 с.

7. Лейбович М.В. Теория удара в задачах и примерах: учеб. пособие / М.В. Лейбович. - Хабаровск: Изд-во Тихоокеан. гос. унта, 2016. $-236 \mathrm{c}$. 